\title{
Hyponatremia, Arginine Vasopressin Dysregulation, and Vasopressin Receptor Antagonism
}

\author{
Amit Rai $^{a} \quad$ Adam Whaley-Connell $^{\mathrm{a}}$ Samy McFarlane ${ }^{\mathrm{b}}$ James R. Sowers ${ }^{\mathrm{c}}$ \\ a Departments of Internal Medicine, Division of Nephrology, University of Missouri-Columbia School of Medicine, \\ and Harry S. Truman VA Medical Center, Columbia, Mo., bState University of New York, Brooklyn, N.Y., and \\ 'University of Arizona Diabetes Center, Tucson, Ariz., USA
}

\section{Key Words}

Aquaporins · Arginine vasopressin • Vasopressin-receptor

antagonist, SIADH $\cdot$ Hyponatremia, vasopressin

dysregulation

\begin{abstract}
Hyponatremia is often associated with arginine vasopressin (AVP) dysregulation that is regulated by the hypothalamoneurohypophyseal tract in response to changes in plasma osmolality, commonly in patients with the syndrome of inappropriate antidiuretic hormone secretion (SIADH). Potentially lethal complications of hyponatremia most frequently involve the central nervous system and include anorexia, fatigue, lethargy, delirium, seizures, hypothermia and coma, and require prompt treatment. Chronic hyponatremia also complicates patient care and is associated with increased morbidity and mortality, particularly among patients with congestive heart failure. Conventional treatments for hyponatremia (e.g. fluid restriction, diuretic treatment, and sodium replacement) may not be effective in all patients and can lead to significant adverse events. Preclinical and clinical trial results have shown that AVP receptor antagonism is a promising approach to the treatment of hyponatremia that directly addresses the effects of increased AVP and consequent decreased aquaresis, the electrolyte-sparing excre-
\end{abstract}

tion of free water. Agents that antagonize $V_{2}$ receptors promote aquaresis and can lead to increased serum sodium. Dual-receptor antagonism, in which both $V_{2}$ and $V_{1 A}$ receptors are blocked, may provide additional benefits in patients with hyponatremia.

Copyright $\odot 2006$ S. Karger AG, Basel

\section{Introduction}

Hyponatremia is typically defined as a serum sodium concentration $\left(\left[\mathrm{Na}^{+}\right]\right)$below $136 \mathrm{mEq} / \mathrm{l}$ and occurs in as many as $6-22 \%$ of hospitalized patients. It can be caused by any condition that increases the ratio of total body water to $\left[\mathrm{Na}^{+}\right]$, and it is often associated with arginine vasopressin (AVP) dysregulation. AVP is a polypeptide hormone released from the hypothalamus, or hypothalamoneurohypophyseal tract, in response to decreases in blood pressure, plasma volume, and/or increases in plasma osmolality. AVP secretion is suppressed when serum osmolality drops below normal. There are two scenarios in which AVP secretion will be sustained, or increased, despite hypo-osmolality. First, when there is dysregulation of cells secreting AVP, which may occur in tumor cells, and is one cause of the syndrome of inappropriate antidiuretic hormone secretion (SIADH). Second, when ei-

\section{KARGER \\ Fax +41613061234 E-Mail karger@karger.ch} www.karger.com
(C) 2006 S. Karger AG, Basel

$0250-8095 / 06 / 0266-0579 \$ 23.50 / 0$

Accessible online at:

www.karger.com/ajn
Prof. James R. Sowers, MD

University of Arizona Diabetes Center

Diabetes Research Center, 1656 E Mabel St, PO Box 245218

Tuscon, AZ 85724-5218 (USA)

E-Mail sowersj@email.arizona.edu 
Table 1. Medical management of hyponatremia

\begin{tabular}{|c|c|c|c|}
\hline Treatment & Mechanism & Daily dose & Limitations \\
\hline Fluid restriction & Decreases free water & Variable & Noncompliance \\
\hline \multicolumn{4}{|c|}{ Pharmacologic inhibition of $A V P$} \\
\hline Demeclocycline & Inhibits renal response to AVP & $1,200 \mathrm{mg}$ followed by $300-900 \mathrm{mg}$ & $\begin{array}{l}\text { Neurotoxicity, polyuria, } \\
\text { photosensitivity, nephrotoxicity }\end{array}$ \\
\hline $\begin{array}{l}\mathrm{V}_{1 \mathrm{~A}} / \mathrm{V}_{2} \text { and } \mathrm{V}_{2} \text { receptor } \\
\text { antagonists }\end{array}$ & Antagonizes AVP & & \\
\hline \multicolumn{4}{|l|}{ Increased solute intake } \\
\hline Furosemide & Increases FWC & Adjust to optimal dose & Ototoxicity, $\mathrm{K}^{+}$depletion \\
\hline Urea & Osmotic diuresis & $30-60 \mathrm{~g}$ & Polyuria, unpalatable GI symptoms \\
\hline
\end{tabular}

ther low or high pressure arterial baroreceptors sense decreased effective circulatory volume, their stimulus for AVP secretion will override osmotic signals and result in hyponatremia associated with cirrhosis, congestive heart failure (CHF) and plasma volume depletion.

Potentially lethal complications of hyponatremia most frequently involve the central nervous system (CNS) and include anorexia, fatigue, lethargy, nausea and vomiting, delirium, seizures, hypothermia, and coma. CNS disturbances are usually attributed to acute water disorders but are increasingly being recognized in patients with chronic hyponatremia due to SIADH. Chronic hyponatremia complicates patient care and is associated with increased morbidity and mortality, particularly among patients with CHF, cirrhosis, and nephrotic syndrome. Conventional treatments for hyponatremia (e.g. fluid restriction and diuretic treatment (table 1) may not be effective in all patients and can lead to significant adverse events.

Water reabsorption in the collecting duct is mediated by vasopressin activation of type- 2 vasopressin $\left(V_{2}\right)$ receptors in the basolateral membrane of collecting duct cells. Activation of $\mathrm{V}_{2}$ receptors results in generation of cAMP and activation of protein kinase A (fig. 1) [1,2]. This results in insertion of aquaporin-2 (AQP2) water channels into the apical membrane of the collecting duct. Once AQP2 is inserted into the apical membrane, $\mathrm{H}_{2} \mathrm{O}$ enters the cells and then exits via AQP3 and 4 in the basolateral membrane, resulting in transcellular water reabsorption. When the stimulus for $\mathrm{H}_{2} \mathrm{O}$ reabsorption ends, AQP2 is removed from the apical membrane by endocytosis $[1,2]$.
Preclinical and clinical trial results have shown that AVP receptor antagonism is a promising approach to the treatment of hyponatremia that directly addresses the effects of increased AVP and consequent decreased aquaresis, the electrolyte-sparing excretion of free water. Agents that antagonize AQP2 promote aquaresis, which results in increased serum $\left[\mathrm{Na}^{+}\right]$. Dual-receptor antagonism, in which both $V_{2}$ and $V_{1 A}$ receptors are blocked, may provide additional benefits in patients with hyponatremia secondary to edematous conditions, particularly CHF.

\section{Clinical Overview of Hyponatremia}

Hyponatremia is typically defined as a decrease in serum $\left[\mathrm{Na}^{+}\right]$to $<136 \mathrm{mEq} / 1$ [3-7] and is usually due to the inability of the kidney to excrete ingested water. Hyponatremia is characterized, and categorized, by osmolality or the measure of solute (sodium) to kilogram of total body water. Hyponatremia can then be classified into three categories, but we will focus on hypo-osmolar hyponatremia which is the most common form (fig. 2) [5]. Hypoosmolar hyponatremia can then be stratified by clinical volume assessment. Euvolemic is associated with SAIDH and AVP dysregulation but hypervolemic hyponatremia in the face of CHF, cirrhosis, or nephrosis can be clinically difficult to assess and treat. Under these conditions, low intravascular volume induces water retention through decreased renal blood flow and baroreceptor-mediated increased secretion of AVP, which can worsen the severity of hyponatremia $[6,8]$. 


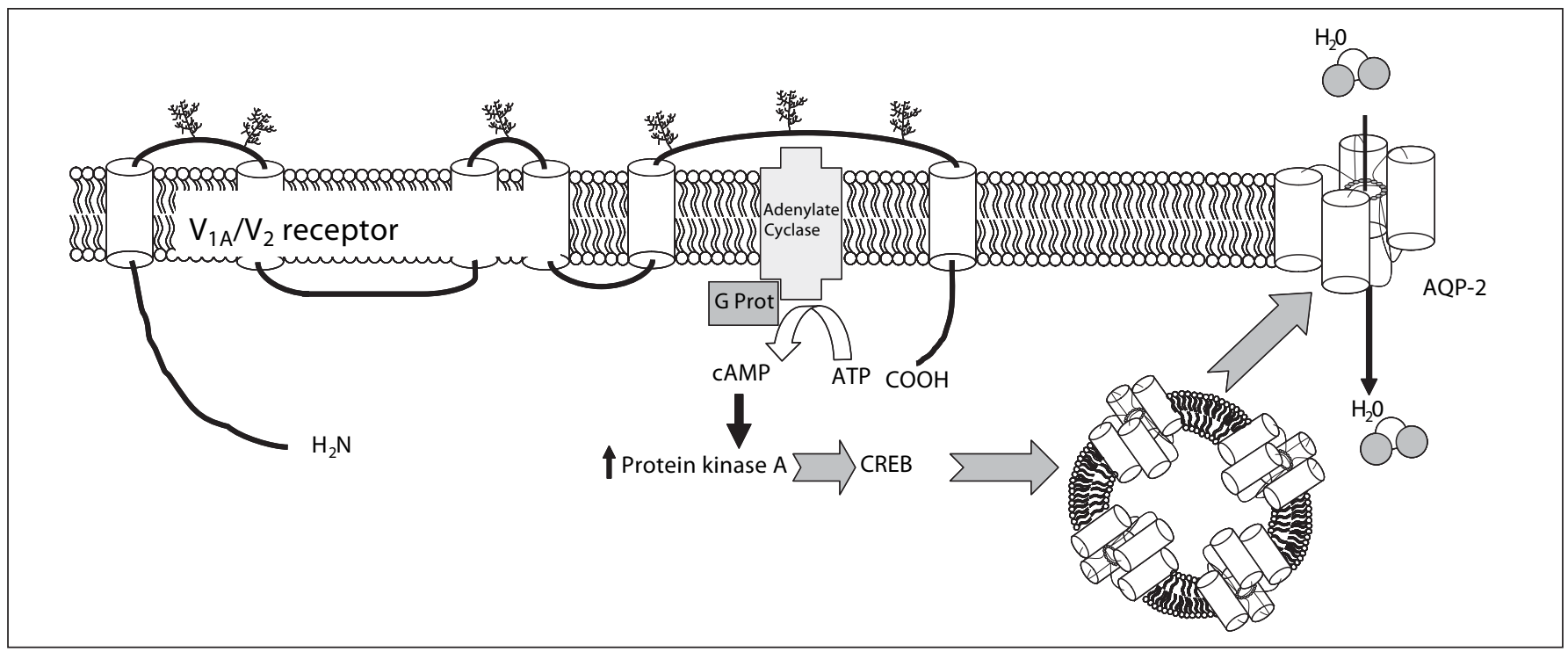

Fig. 1. Activation of the vasopressin $\mathrm{V}_{1 \mathrm{~A}}$ or $\mathrm{V}_{2}$ receptor leads to increased protein kinase and stimulation of CREBS thus activating aquaporin-2 (AQP2) channel to allow water $\left(\mathrm{H}_{2} \mathrm{O}\right)$ to pass. This process is mediated via adenylate cyclase-activated cAMP.

Fig. 2. Algorithm for the diagnosis of hyponatremia. BUN = Blood urea nitrogen; HCTZ = hydrochlorothiazide.

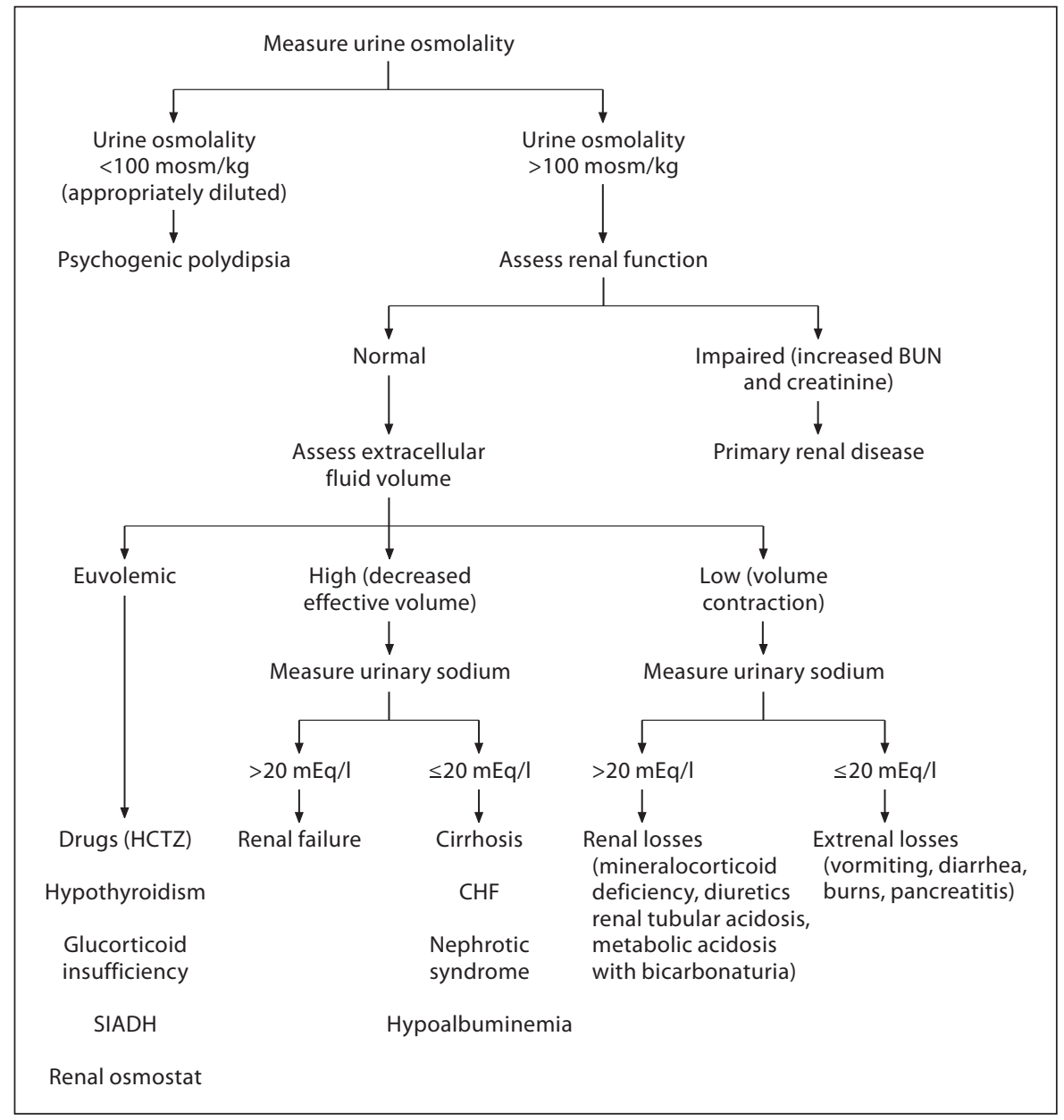




\section{Prevalence of Hyponatremia}

Hyponatremia is a common electrolyte disorder; its reported prevalence among hospitalized patients is 6$22 \%[3,9,10]$. One prospective study indicated that the incidence and prevalence of severe hyponatremia (defined as $\left.\left[\mathrm{Na}^{+}\right]<125 \mathrm{mEq} / \mathrm{l}\right)$ were 1.5 and 2.6 per 100 hospitalized patients per day, respectively [11]. Another prospective study reported that $30 \%$ of patients in intensive care units had hyponatremia [12]. Many hospitalized patients have hyponatremia at the time of admission; in one study, one third of adults with hyponatremia had serum $\left[\mathrm{Na}^{+}\right]<130 \mathrm{mEq} / \mathrm{l}$ at the time of admission [13]. Hyponatremia is also a frequent consequence of various surgical procedures, including pelvic [14], spinal [15], and pituitary surgery [16].

Hyponatremia is particularly prevalent in the elderly, in part because of an age-related decline in renal function. In a longitudinal assessment of 119 nursing home residents older than 60 years, $53 \%$ had at least one episode of hyponatremia during a 12-month follow-up period. The incidence of hyponatremia among these patients was $18 \%$, substantially higher than the $8 \%$ for age-matched non-institutionalized persons living in the community [17].

\section{Hyponatremia-Associated Mortality and Morbidity}

Hyponatremia is associated with a significantly increased risk of death $[4,18,19]$. In addition, hyponatremia that is not treated promptly and effectively can worsen outcomes among patients with chronic disease, most notably CHF [5]. In one large scale cohort study of 4,123 geriatric patients, the prevalence of hyponatremia on hospital admission was 3.5\% (4.6\% in women and 2.6\% in men), and the in-hospital mortality among that population was 16.0 versus $8.0 \%$ among those admitted without hyponatremia. A logistic regression analysis showed that hyponatremia at the time of hospital admission was a significant independent predictor of mortality [20]. In a series of 234 patients admitted to hospital with acute exacerbation of CHF, severe hyponatremia was significantly correlated with an increased risk of death [21]. Similarly, serum $\left[\mathrm{Na}^{+}\right]$was a primary determinant of survival in a cohort of 203 patients with severe CHF and hyponatremia, among whom the median survival period was significantly shorter (174 days) than that among patients with CHF without hyponatremia (373 days) [22].

Hyponatremia is also associated with a significantly poor prognosis among patients hospitalized for cirrhosis. In one series of 156 patients (191 hospital admis- sions), the death rate was $26.3 \%$ among cirrhotic patients with hyponatremia versus $8.9 \%$ among those without hyponatremia [23]. Hyponatremia is also associated with significant morbidity $[5,24]$ and can produce a wide range of deleterious changes involving almost all body systems, the most important and potentially lethal involving the CNS. Although mild and chronic hyponatremia is often asymptomatic, the symptoms associated with this disorder become more pronounced as serum $\left[\mathrm{Na}^{+}\right]$decreases. Very low serum $\left[\mathrm{Na}^{+}\right](<125 \mathrm{mEq} / \mathrm{l})$ may produce CNS-related symptoms that include anorexia, fatigue, lethargy, delirium, seizures, hypothermia, and coma. Cheyne-Stokes respiration or respiratory arrest and pathologic reflexes may develop along with worsening cerebral edema in patients with severe hyponatremia. Severe acute hyponatremia can lead to brainstem herniation, and a rapid drop in serum $\left[\mathrm{Na}^{+}\right]$to $<115 \mathrm{mEq} / \mathrm{l}$ can cause sudden death $[5,6]$. The treatment of hyponatremia is complex and differs according to its rate of onset [25]. Untreated acute hyponatremia (developing within $48 \mathrm{~h}$ ) is more likely to cause cerebral edema and neurologic damage than is chronic hyponatremia (developing over $48 \mathrm{~h}$ ); however, persons with chronic hyponatremia are at risk for osmotic demyelination if the correction of serum $\left[\mathrm{Na}^{+}\right]$is too rapid [26]. Osmotic demyelination may lead to severe neurologic dysfunction, manifested by quadriplegia, pseudobulbar palsy, seizures, and coma. These symptoms may develop several days after aggressive treatment and are often irreversible $[5,27]$.

\section{Etiology of Hyponatremia}

AVP dysregulation is the most common cause of hypoosmolar hyponatremia [13], the prototype being SIADH. Euvolemic hyponatremia associated with SIADH is caused by the aberrant or sustained secretion of AVP in the absence of an appropriate osmotic stimulus (e.g. elevated plasma osmolality). Elevated AVP secretion leads to water retention by the kidney and, in patients with SIADH, AVP secretion is not suppressed when plasma osmolality falls below the normal threshold for stimulation of AVP secretion [28]. This syndrome is particularly common in hospitalized and elderly patients [6]. In one study, for example, $78 \%$ of hyponatremic patients in a nursing home population had SIADH [17]. The increased risk for SIADH in older individuals may be related to both increased AVP secretion and changes in renal anatomy and vasculature that occur with age [6]. 


\section{AVP and Its Role in Water Balance and Blood Pressure Regulation}

Serum $\left[\mathrm{Na}^{+}\right]$is regulated by thirst, AVP, and the reninangiotensin-aldosterone system (RAAS). AVP is a cyclic nonapeptide hormone synthesized by magnocellular and parvocellular neurons in the supraoptic and paraventricular nuclei of the hypothalamus. It is transported down the pituitary stalk in the axons of these neurosecretory cells and stored in nerve endings in the posterior lobe of the pituitary gland [29]. Release of AVP is triggered by the activation of osmoreceptors in the organum vasculosum of the lamina terminalis or baroreceptor-associated afferents that innervate brainstem neurons that, in turn, project to the hypothalamus $[29,30]$. Osmoreceptor-induced AVP release is triggered by increased plasma osmolality, while baroreceptor-induced AVP release is stimulated by either a decrease in blood pressure or relative decrease in blood volume. In response to these stimuli, AVP maintains plasma osmolality through renal free water regulation [31]. Osmotic regulation of AVP is sensitive to a $1-2 \%$ change in plasma osmolality, but when low plasma osmolality occurs with low blood pressure, the baroreceptor-mediated release of AVP overrides the suppressive effect of hypo-osmolality. This reaction can exacerbate water retention and worsen hyponatremia.

\section{AVP Receptors}

The actions of AVP are mediated by three structurally distinct $G$ protein-coupled AVP receptor subtypes $\left(V_{1 A}\right.$, $\mathrm{V}_{2}$, and $\mathrm{V}_{3}$ [or $\left.\mathrm{V}_{1 \mathrm{~B}}\right]$ ) $[32,33]$. The $\mathrm{V}_{1 \mathrm{~A}}$ (vascular) AVP receptor is expressed on vascular smooth muscle cells, the myocardium, and platelets and in the liver. At these locations, the receptor activates phosphoinositide pathways that stimulate vasoconstriction, myocardial contraction, platelet aggregation, and glycogenolysis, respectively [34]. The negative impact of AVP on hemodynamics and cardiac remodeling (e.g. chronic vasoconstriction and vascular hypertrophy) are mediated through the $\mathrm{V}_{1 \mathrm{~A}}$ receptor $[31,35]$.

The $\mathrm{V}_{2}$ (renal) AVP receptor is expressed in the vascular endothelium and on cells of the renal distal tubule and collecting duct. This receptor activates cyclic adenosine monophosphate and protein kinase A via Gs and adenylate cyclase to stimulate the release of von Willebrand's factor from endothelial cells and to increase water permeability, and thus reabsorption, in the collecting duct of the kidney [34]. Permeability is increased by the protein kinase A-mediated synthesis and insertion of AQP2 water channels into the apical membranes of cells lining the collecting duct $[32,36]$. Expression of the $\mathrm{V}_{2}$ receptor may be downregulated in renal cells in response to sustained high levels of AVP. This downregulation is adaptive and helps maintain fluid-electrolyte balance in the presence of chronically elevated AVP [37]. The $\mathrm{V}_{3}$ (pituitary) AVP receptor (also referred to as the $\mathrm{V}_{1 \mathrm{~B}}$ receptor) is expressed by cells in the anterior pituitary, where it is involved in the regulation of adenocorticotrophic hormone release through phosphoinositide pathways [32]. The human $V_{3}$ receptor is pharmacologically distinct from the $V_{1 A}$ and $V_{2}$ receptors [33].

\section{Aquaporins}

The AQPs are a family of membrane proteins that allow water to pass through biologic membranes. There are 4 major types of renal AQPs located in the distal tubules. Each contains six transmembrane scanning domains forming a central pore that allows water to be reabsorbed from the urine [36]. When AVP binds to the $\mathrm{V}_{2}$ receptor, the cascade of events previously described results in phosphorylation of regulatory proteins, including AQP2, a water channel in the principal cells of the collecting duct [38]. Upon phosphorylation, AQP2 is inserted into the apical plasma membrane, where it mediates free water reabsorption $[36,37]$. This water is then removed to the peritubular capillaries via AQP3- or 4-mediated transport. The removal of AVP from its receptor causes AQP2 to be internalized, which reduces membrane permeability. In normal states, escape from anti-diuresis is accompanied by the downregulation of both AQP and AVP receptors in the kidney [38].

\section{Syndrome of Inappropriate Secretion of Antidiuretic \\ Hormone (SIADH)}

Bartter and Schwartz [39] first described criteria for SIADH that are still applicable today: hypotonic hyponatremia, urine osmolality greater than appropriate for the concomitant plasma osmolality, increased natriuresis, absence of edema or volume depletion, and normal renal and adrenal function [40]. SIADH is a relatively common cause of hyponatremia that results from the aberrant or sustained secretion of AVP by the hypothalamic-pituitary system [13, 41]. Elevated AVP secretion leads to renal water retention and extracellular fluid expansion, which is compensated for by increased urinary $\mathrm{Na}^{+}$excretion. The combination of water retention and $\mathrm{Na}^{+}$excretion leads to hyponatremia. This syndrome develops when there is continued ingestion or infusion of fluids in the presence of persistent antidiuretic activity, almost always due to elevated concentrations of plas- 
ma AVP. Patients with SIADH will continue to drink despite having hypotonic hyponatremia, since the inhibitory effect of osmoregulated thirst is not sufficiently strong to stop drinking [7]. Because the regulation of AVP secretion fails in patients with SIADH $[28,41]$, total body water increases and hypotonic hyponatremia ensues [28].

Osmoregulated AVP release can be measured as plasma AVP in response to infusion of hypertonic saline. This procedure has been used to detect four patterns of AVP dysregulation in patients with SIADH (fig. 2) [7]. The most common (in $40 \%$ of patients with SIADH) pattern is the excessive and unregulated release of AVP, which is unrelated to plasma osmolality. In the second most common pattern ( $\sim 30 \%$ of patients), referred to as 'reset osmostat', AVP release continues to regulate water excretion at a lower plasma osmolality setpoint. A third pattern is characterized by an inability to stop AVP secretion at low plasma osmolalities, but the osmoregulation of AVP is otherwise normal. In the fourth pattern, the normal osmoregulation of AVP secretion is normal, even as SIADH persists ( $<10 \%$ of patients) [7].

\section{Causes of Hyponatremia}

SIADH resulting in hyponatremia may arise in response to a wide range of conditions. Common causes include: cancer that induces ectopic AVP production; HIV/AIDS; pulmonary disease; endocrine disease; neurologic disease or trauma, and surgery (fig. 2) [6, 16, 42]. The synthesis and release of AVP are also chronically elevated in patients with CHF [31]. In advanced CHF, low cardiac output is sensed by baroreceptors that stimulate further AVP secretion to increase vascular resistance and salt/water retention in the kidney [8].

\section{Postsurgical SIADH and Hyponatremia}

Hyponatremia, produced by either SIADH or the cerebral salt-wasting (CSW) syndrome, occurs in 9-35\% of patients after pituitary surgery, possibly as a function of damage to the hypothalamic-pituitary tract [16]. Clinical distinction between hyponatremia secondary to SIADH and that caused by CSW may be difficult. The critical difference between the two conditions is that CSW involves renal salt loss leading to hyponatremia and volume loss, whereas SIADH results in hyponatremia (typically euvolemic) related to water retention [43].

Hyponatremia is relatively common after general surgery. In a prospective study of 1,088 patients who underwent a variety of surgeries, including cardiovascular, gastrointestinal, renal transplantation, and orthopedic procedures, about $5 \%$ demonstrated the disorder. Overzealous administration of hypotonic fluid can contribute to postoperative hyponatremia, which is often attributed to SIADH [44].

\section{Drug-Associated Hyponatremia}

A wide range of drugs has been associated with the development of hyponatremia and SIADH [6], including commonly used nonsteroidal anti-inflammatory drugs, acetaminophen, nicotine, the oral antidiabetic agent chlorpropamide, and the antiepileptic drugs carbamazepine and oxcarbazepine [7, 42]. Antineoplastic agents, including vincristine, vinblastine, cyclophosphamide, and ifosfamide, and the antipsychotic medications, thiothixene and haloperidol, can also cause SIADH by increasing AVP release [42]. Angiotensin-converting enzyme inhibitors may also cause SIADH, but the mechanism underlying this effect has not yet been determined [45]. For example, diuretics can stimulate AVP release by inducing hypovolemia. They also impair urinary dilution and alter osmoreceptor sensitivity and thirst by depleting potassium [25]. Thiazide diuretics interfere with urinary dilution at the distal tubule and may be associated with a particularly high risk for the development of hyponatremia. In a review of 129 case reports of hyponatremia, thiazide diuretics were involved in $73 \%$ of cases [18].

The tricyclic antidepressant, clofibrate, and the serotonin-selective reuptake inhibitors (SSRIs) can lead to increased AVP release and hyponatremia [42]. In a series of patients taking SSRIs, symptomatic hyponatremia due to SIADH occurred in $12.5 \%$ and asymptomatic hyponatremia was noted in an additional $12.5 \%$ [45]. In a retrospective case-note study, hyponatremia occurred in $40 \%$ of 15 elderly patients with depression within 2 weeks after the initiation of treatment with the SSRI, paroxetine. The secretion of AVP was elevated in these patients despite their having low serum osmolality [46]. A second study by the same group revealed the rapid development of hyponatremia in $12 \%$ of a cohort of 75 elderly depressed patients who initiated therapy with paroxetine [47]. Case reports describing the development of hyponatremia in elderly patients who had hypertension and depression suggest that the combination of an SSRI and a thiazide diuretic may act synergistically to impair renal free water clearance (FWC), leading to severe hyponatremia [48]. 


\section{AVP Dysregulation and Abnormal Water Balance in the Elderly}

Elderly individuals are at the highest risk of having hyponatremia, owing to a number of predisposing, agerelated physiologic changes [6]. First, an age-related decrease in total body water (relative and absolute) renders elderly persons more susceptible to water imbalance [49, 50]. Second, the thirst mechanism diminishes with age, thereby significantly impairing the ability to maintain homeostasis and increasing the risk of dehydration [49, 51]. Third, the aging kidney contains fewer glomeruli, leading to decreased renal blood flow and a lower glomerular filtration rate. This change in renal function results in increased passive reabsorption of water in the distal tubule and impaired urinary diluting capacity [6]. The increased secretion of AVP and reduced sensitivity of the cyclic adenosine monophosphate response to AVP in the aging kidney can also decrease urinary dilution and FWC $[6,52]$.

The risks of the dysregulation of water balance and hyponatremia are also increased in older individuals by an age-related rise in AVP secretion per unit increase in plasma osmolality. This change may be caused by the enhanced sensitivity of osmoreceptors or increased osmoreceptor-induced AVP release in older individuals [7].

The risks for hyponatremia in the elderly are also elevated when they take certain drugs (e.g. diuretics, antidepressants) known to be associated with the development of this condition $[4,47]$.

\section{AVP Dysregulation and Fluid Retention in CHF}

Reduced cardiac output in patients with CHF stimulates increased secretion of AVP and the activation of both the RAAS and the sympathetic nervous system [53, 54]. The synthesis and plasma levels of AVP are significantly and chronically elevated in patients with CHF despite the presence of volume overload, atrial distension, hyponatremia, and low plasma osmolality that would normally inhibit AVP release [31,55]. The non-osmotic release of AVP is apparently caused by disturbances in circulatory homeostasis, such as arterial underfilling [55]. Elevated levels of AVP have adverse effects on hemodynamics and cardiac remodeling and potentiate the vascular and cardiac effects of norepinephrine and angiotensin II [31]. Excessive AVP secretion is a possible contributing factor for increased systolic and diastolic wall stress via $\mathrm{V}_{1 \mathrm{~A}^{-}}$and $\mathrm{V}_{2}$-mediated effects on the peripheral vasculature and on water retention [56]. By increased activation of $\mathrm{V}_{1 \mathrm{~A}}$ receptors, AVP may have a direct adverse affect on myocardial contractility and cell growth [56, 57]. Indeed, hyponatremia induced by excess AVP has been shown to be an independent risk factor for death in patients with CHF [58].

\section{AVP Dysregulation and Hyponatremia in Cirrhosis}

Hyponatremia is frequently seen in patients with cirrhosis. Evidence suggests the hyponatremia of cirrhosis is dilutional and is a result of impaired water excretion. Patients with cirrhosis and ascites usually have a marked decrease in systemic vascular resistance and mean arterial pressure. In an animal study of cirrhosis, these changes were related to increased generation of nitric oxide [59]. Further, a reduction in pressure sensed by baroreceptors leads to activation of neurohormonal mechanisms including RAAS, sympathetic nervous system activation and more importantly AVP release in an attempt to restore perfusion $[32,60]$. Another renal mechanism for water retention may be reduced renal prostaglandin synthesis and decreased distal tubule delivery [60]. In the early course of disease, water excretion is usually normal but becomes increasingly impaired as the liver disease progresses and is largely related to the increased release of AVP. The increase in AVP secretion is roughly proportional to the severity of the disease, so the degree of hyponatremia may also correlate with the severity of parenchymal liver disease [32].

\section{AVP Receptor Antagonism}

The selective blockade of the appropriate AVP receptors is a rational therapeutic approach in the treatment of dilutional hyponatremia $[29,32,61,62]$. These agents treat the effects of increased serum levels of AVP more directly than conventional therapies, such as fluid restriction, saline infusions, diuretics, lithium, demeclocycline, and urea (table 1) $[25,63]$. The $\mathrm{V}_{2}$ receptor, which is expressed primarily in the kidney, presents an ideal target for modulating the effects of AVP on water balance [32]. During the normal renal escape from water loading and AVP elevation, expression of the $\mathrm{V}_{2}$ receptor and its associated AQP is downregulated [37, 38]. Unlike diuretics, $V_{2}$ receptor antagonists stimulate free water excretion without $\mathrm{Na}^{+}$or $\mathrm{K}^{+}$loss (fig. 1) [64, 65]. Antagonism of the $\mathrm{V}_{2}$ receptor stimulates water excretion without compen- 
satory activation of the RAAS, another undesirable effect of loop diuretics [66]. The use of an AVP receptor antagonist to treat hyponatremia has other advantages over existing therapies. In patients with CHF, AVP antagonism has the potential to produce effective and sustained reductions in congestion without worsening renal function, potassium depletion, or hypotension that may be associated with diuretics [67]. In low-output $\mathrm{CHF}, \mathrm{V}_{2}$ receptor antagonists can correct the associated conditions of hyponatremia, hypo-osmolality, and water retention [54]. AVP receptor antagonists that block both $\mathrm{V}_{2}$ and $\mathrm{V}_{1 \mathrm{~A}}$ receptors may provide additional benefits in patients with hyponatremia caused by edematous conditions, such as CHF, because they have the potential to counteract water retention in the kidney, inhibit ventricular remodeling, lower blood pressure, and decrease the risk of coronary vasospasm $[68,69]$.

\section{$V_{2}$ Antagonism in Hyponatremia}

Antagonists of $\mathrm{V}_{1 \mathrm{~A}}$ and $\mathrm{V}_{2}$ receptors are currently under investigation for the treatment of hyponatremia due to CHF, hypertension, cirrhosis, and the nephritic syndrome $[32,61]$. These drugs were effective, safe, and well tolerated in early-stage clinical trials [70]. The inhibition of AVP at the $\mathrm{V}_{2}$ receptor induces aquaresis (fig. 1), the elimination of free water without depleting electrolytes or activating neurohormonal systems [34]. Thus, these antagonists appear to be particularly useful for treating water retention and hyponatremia in SIADH and hepatic cirrhosis $[32,62]$.

\section{SIADH}

In a study of 6 patients with SIADH and 5 with cirrhosis [71], treatment twice daily with 50 or $100 \mathrm{mg}$ of the oral $\mathrm{V}_{2}$ receptor antagonist lixivaptan (VPA-985) increased the serum $\left[\mathrm{Na}^{+}\right]$from 126 to $133 \mathrm{mEq} / \mathrm{l}$ during a 24 -hour period in patients with SIADH. This rise was associated with a significant decrease in $\mathrm{Na}^{+}$excretion, from 82 to $45 \mathrm{mEq} / \mathrm{l} / 24 \mathrm{~h}$. Lixivaptan $(25,125$, or $250 \mathrm{mg} /$ day) has also been evaluated in a larger sample of $44 \mathrm{pa}-$ tients with hyponatremia. As in the smaller study, lixivaptan produced a significantly greater aquaretic response than the placebo did, with significant dose-related increases in FWC and serum $\left[\mathrm{Na}^{+}\right][72]$.

\section{$\mathrm{CHF}$}

The $\mathrm{V}_{2}$ receptor antagonist tolvaptan has been evaluated in patients with CHF in two large-scale studies. The first study enrolled 254 patients with CHF, $28 \%$ whose serum $\left[\mathrm{Na}^{+}\right]$was $<136 \mathrm{mEq} / \mathrm{l}$ at baseline. Patients were randomly assigned to 25 days of treatment with placebo or 30,45 , or $60 \mathrm{mg}$ tolvaptan without fluid restriction and while maintaining stable doses of furosemide [73]. In the subgroup of patients with hyponatremia, tolvaptan produced significantly greater increases in serum $\left[\mathrm{Na}^{+}\right]$than placebo, with the majority of patients achieving normal serum $\left[\mathrm{Na}^{+}\right]$by day 1 and throughout the end of treatment [73]. In a second randomized, double-blind, placebo-controlled, parallel-group trial, the safety and efficacy of tolvaptan $(30,60$, or $90 \mathrm{mg} /$ day for up to 60 days $)$ was evaluated in 319 patients with a left ventricular ejection fraction of $<40 \%$ who were hospitalized for worsening symptoms of CHF [74]. Sixty-eight patients had hyponatremia (serum $\left[\mathrm{Na}^{+}\right]<136 \mathrm{mEq} / \mathrm{l}$ ) at baseline. Tolvaptan produced a rapid increase in serum $\left[\mathrm{Na}^{+}\right]$in this subpopulation, and often a normalization that persisted throughout the study [74]. A single dose of OPC-31260 $(0.25$ or $0.5 \mathrm{mg} / \mathrm{kg})$ increased urine volume and decreased urinary osmolality to $<225 \mathrm{mosm} / \mathrm{kg}$ in 11 patients with hyponatremia and SIADH [75].

Combination therapy with AVP antagonism and ACE inhibition has been studied in animal models and shown to improve left ventricular function [57]. Investigators demonstrated that combination therapy using conivaptan with or without captopril in a rat model of CHF showed an increase in free-water excretion and also significantly lowered blood pressure, ventricular (left and right) and lung mass. Indeed, simultaneous antagonism of $V_{1}$ and $V_{2}$ receptors and inhibition of the renin angiotensin system may be effective in managing hyponatremia in CHF.

\section{Cirrhosis}

In a study of 8 patients with cirrhosis and ascites or peripheral edema, a single 30-mg dose of OPC-31260 significantly increased the urinary excretion rate within $2 \mathrm{~h}$ and significantly lowered urine osmolality $2-4 \mathrm{~h}$ after administration. FWC was also significantly increased within $4 \mathrm{~h}$ after administration [76].

Further, $\mathrm{V}_{2}$ receptor antagonism has also shown efficacy in correction of dilutional hyponatremia in patients with cirrhosis in a study of 60 patients [60]. Patients were randomized to placebo or 50 or $100 \mathrm{mg}$ lixivaptan (VPA985) twice a day with concomitant fluid restriction. There was a significant dose-dependent increase in the serum sodium concentration in treated patients by at least $5 \mathrm{mmol} / \mathrm{l}: 67 \%$ in the $200-\mathrm{mg}$ group; $45 \%$ in the $100-\mathrm{mg}$ group, and only $15 \%$ in the placebo group $(\mathrm{p}<0.01)$. A complete response (serum sodium concentration 
$>136 \mathrm{mmol} / \mathrm{l}$ ) was observed in $50 \%$ of patients in the 200 $\mathrm{mg}$ group, $27 \%$ of patients in the $100-\mathrm{mg}$ group, and none in the placebo group ( $\mathrm{p}<0.01$ and $\mathrm{p}<0.05$ for 200 and $100 \mathrm{mg}$ VPA compared with placebo group, respectively) [60]. There was no significant difference between groups in the development of renal insufficiency noticed. Indeed, $\mathrm{V}_{2}$ receptor antagonism may increase the plasma AVP concentration by affecting a negative feedback mechanism which may lead to an unopposed hyperstimulation of the vasoconstrictor $\mathrm{V}_{1}$ receptors. Theoretical potential hyperstimulation of the vasoconstrictor $\mathrm{V}_{1}$ receptors may have a beneficial effect in patients with cirrhosis by decreasing pressure in the portal circulation and potentially decreasing risk of variceal bleeding [32].

\section{$\mathbf{V}_{1 \mathrm{~A}} / \mathbf{V}_{\mathbf{2}}$ Receptor Antagonist}

A $V_{1 A} / V_{2}$ receptor antagonist provides $V_{2}$-mediated renal aquaresis and may suppress the negative hemodynamic and cardiac effects caused by activation of the $V_{1 A}$ receptor $[34,67]$. Conivaptan (YM-087) is currently the only agent in this class [77] and has recently been approved by FDA. In an early pharmacokinetic/pharmacodynamic study of conivaptan in healthy volunteers, the drug was well tolerated, increased urine flow, lowered urine osmolality, and increased plasma osmolality [78].

In several small-scale open-label studies, conivaptan produced significant aquaresis in patients with either $\mathrm{CHF}$ or SIADH and hyponatremia. In a study of $6 \mathrm{pa}-$ tients who had hyponatremia and CHF before undergoing heart transplantation, conivaptan (20-120 mg twice daily) increased FWC and serum $\left[\mathrm{Na}^{+}\right]$, changes that persisted for several weeks after the discontinuation of conivaptan [79]. In another open-label study of 6 patients with hyponatremia and CHF awaiting transplant, conivaptan (10-60 mg twice daily) increased the average serum $\left[\mathrm{Na}^{+}\right]$by $5 \mathrm{mEq} / \mathrm{l}$ and maintained it $\geq 4 \mathrm{mEq} / \mathrm{l}$ above baseline for 1 week after the end of treatment. Conivaptan also decreased urine osmolality and increased urine output and FWC [80]. The effects of intravenous conivaptan (up to $40 \mathrm{mg}$ day) were evaluated in 8 patients with hyponatremia (4 patients with SIADH and 4 with CHF). After 3 days of treatment, the patients' average $\left[\mathrm{Na}^{+}\right]$increased to $131 \mathrm{mEq} / \mathrm{l}$ and their urinary $\left[\mathrm{Na}^{+}\right]$ osmolality decreased from 380 to $292 \mathrm{mosm} / \mathrm{kg}$. Their FWC increased from 364 to $484 \mathrm{ml}$ [81].

In a larger double-blind trial, 142 patients with symptomatic CHF (New York Heart Association class III and IV) were randomly assigned to receive a single intrave- nous dose of conivaptan $(10,20$, or $40 \mathrm{mg})$ or placebo. The 20 - and 40-mg conivaptan doses reduced pulmonary capillary wedge pressure significantly more than placebo. Conivaptan also increased urine output significantly during the first $4 \mathrm{~h}$ after administration. In addition, conivaptan had no significant effects on blood pressure or heart rate in patients with advanced $\mathrm{CHF}$ [68]. Conivaptan (20-80 mg daily) was administered to 5 patients who had SIADH and a baseline $\left[\mathrm{Na}^{+}\right]$of $<132 \mathrm{mEq} / \mathrm{l}$. In each of these patients, conivaptan normalized $\left[\mathrm{Na}^{+}\right]$, increased FWC, and decreased urine osmolality [82]. Conivaptan has also been evaluated in several recently completed clinical trials of patients with euvolemic or hypervolemic hyponatremia. In a randomized, double-blind, multicenter, placebo-controlled, parallelgroup study, intravenous conivaptan (a 20-mg loading dose followed by continuous infusion of 40 or $80 \mathrm{mg} /$ day for 4 days) was compared with placebo in 84 patients. Both conivaptan doses were significantly more effective than placebo in increasing serum $\left[\mathrm{Na}^{+}\right]$and effective water clearance, a measure of electrolyte-free water excretion [83]. In two similar studies, 83 and 74 patients, respectively, with euvolemic or hypervolemic hyponatremia were given oral conivaptan, 40 or $80 \mathrm{mg} /$ day, or placebo for 5 days. Results indicated that conivaptan improved $\left[\mathrm{Na}^{+}\right]$and other efficacy measures significantly more than placebo $[84,85]$.

\section{Conclusions}

Hyponatremia is a common electrolyte disorder that affects as many as $22 \%$ of hospitalized patients. It can be caused by any condition that increases the ratio of total body water to serum $\left[\mathrm{Na}^{+}\right]$, and it is often associated with AVP dysregulation, such as in SIADH. The dysregulation of AVP secretion and hyponatremia are particularly common in the elderly and caused by many drugs and certain types of surgery. Conventional treatments for hyponatremia (e.g. fluid restriction, diuretic treatment, and $\mathrm{Na}^{+}$replacement) may not be effective in all patients with hyponatremia and can result in significant adverse events. Preclinical and clinical trial results have shown that aquaresis achieved with AVP receptor antagonism is a rational and highly promising approach to the treatment of hyponatremia that, unlike diuretic therapy, directly addresses the effects of elevated AVP that cause this clinically important electrolyte imbalance. AVP antagonists promote the renal excretion of free water and thereby increase serum $\left[\mathrm{Na}^{+}\right]$, without activating neurohormonal systems. 


\section{References}

1 Nielsen S, Frokiaer J, Marples, et al: Aquaporins in the kidney: from molecules to medicine. Physiol Rev 2002;82:205-244.

2 Bertuccio CA, Ibarra FR, Toledo JE, et al: Endogenous vasopressin regulates $\mathrm{Na}-\mathrm{K}$ ATPase and $\mathrm{Na}^{+}-\mathrm{K}^{+}-\mathrm{Cl}$ cotransporter $r b s c-1$ in rat outer medulla. Am J Physiol Renal Physiol 2002;282:F265-F270.

-3 Gross P, Wehrle R, Bussemaker E: Hyponatremia: pathophysiology, differential diagnosis and new aspects of treatment. Clin Nephrol 1996;46:273-276.

-4 Goh KP: Management of hyponatremia. Am Fam Physician 2004;69:2387-2394.

$\checkmark 5$ Adrogue HJ, Madias NE: Hyponatremia. N Engl J Med 2000;342:1581-1589.

-6 Miller M: Syndromes of excess antidiuretic hormone release. Crit Care Clin 2001;17:1123.

7 Baylis PH: The syndrome of inappropriate antidiuretic hormone secretion. Int J Biochem Cell Biol 2003;35:1495-1499.

$\checkmark 8$ Wong LL, Verbalis JG: Vasopressin V2 receptor antagonists. Cardiovasc Res 2001;51: 391-402.

$\checkmark 9$ Han DS, Cho BS: Therapeutic approach to hyponatremia. Nephron 2002;92(suppl 1):913.

$>10$ Flear CT, Gill GV, Burn J: Hyponatraemia: mechanisms and management. Lancet 1981; 2:26-31.

11 Natkunam A, Shek CC, Swaminathan R: Hyponatremia in a hospital population. J Med 1991;22:83-96.

$\checkmark 12$ DeVita MV, Gardenswartz MH, Konecky A, Zabetakis PM: Incidence and etiology of hyponatremia in an intensive care unit. Clin Nephrol 1990;34:163-166.

$\checkmark 13$ Anderson RJ, Chung HM, Kluge R, Schrier RW: Hyponatremia: a prospective analysis of its epidemiology and the pathogenetic role of vasopressin. Ann Intern Med 1985;102:164168.

$\checkmark 14$ Amede FJ, James KA, Michelis MF, Gleim GW: Changes in serum sodium, sodium balance, water balance, and plasma hormone levels as the result of pelvic surgery in women. Int Urol Nephrol 2002;34:545-550.

15 Amini A, Schmidt MH: Syndrome of inappropriate secretion of antidiuretic hormone and hyponatremia after spinal surgery. Neurosurg Focus 2004;16:E10.

-16 Casulari LA, Costa KN, Albuquerque RC, et al: Differential diagnosis and treatment of hyponatremia following pituitary surgery. J Neurosurg Sci 2004;48:11-18

-17 Miller M, Morley JE, Rubenstein LZ: Hyponatremia in a nursing home population. J Am Geriatr Soc 1995;43:1410-1413.

-18 Sonnenblick M, Friedlander Y, Rosin AJ: Diuretic-induced severe hyponatremia. Review and analysis of 129 reported patients. Chest 1993;103:601-606.
19 Lee CT, Guo HR, Chen JB: Hyponatremia in the emergency department. Am J Emerg Med 200;18:264-268.

20 Terzian C, Frye EB, Piotrowski ZH: Admis sion hyponatremia in the elderly: factors influencing prognosis. J Gen Intern Med 1994; 9:89-91.

21 Chen MC, Chang HW, Cheng CI, et al: Risk stratification of in-hospital mortality in patients hospitalized for chronic congestive heart failure secondary to non-ischemic cardiomyopathy. Cardiology 2003;100:136142.

22 Lee WH, Packer M: Prognostic importance of serum sodium concentration and its modification by converting-enzyme inhibition in patients with severe chronic heart failure. Circulation 1986;73:257-267.

23 Borroni G, Maggi A, Sangiovanni A, et al: Clinical relevance of hyponatraemia for the hospital outcome of cirrhotic patients. Dig Liver Dis 2000;32:605-610.

24 Fried LF, Palevsky PM: Hyponatremia and hypernatremia. Med Clin North Am 1997; 81:585-609.

25 Kumar S, Berl T: Sodium. Lancet 1998;352: 220-228.

26 Decaux G, Soupart A: Treatment of symptomatic hyponatremia. Am J Med Sci 2003 326:25-30.

27 Lin SH, Hsu YJ, Chiu JS, et al: Osmotic demyelination syndrome: a potentially avoidable disaster. QJM 2003;96:935-947.

28 Verbalis JG: Vasopressin V2 receptor antagonists. J Mol Endocrinol 2002;29:1-9.

29 Ishikawa SE, Schrier RW: Pathophysiological roles of arginine vasopressin and aquaporin-2 in impaired water excretion. Clin Endocrinol 2003;58:1-17.

30 Robertson GL: Antidiuretic hormone. Normal and disordered function. Endocrinol Metab Clin North Am 2001;30:671-694.

-31 Lee CR, Watkins ML, Patterson JH, et al: Vasopressin: a new target for the treatment of heart failure. Am Heart J 2003;146:9-18.

32 Ferguson JW, Therapondos G, Newby DE, Hayes PC: Therapeutic role of vasopressin receptor antagonism in patients with liver cirrhosis. Clin Sci 2003;105:1-8.

33 Thibonnier M, Coles P, Thibonnier A, Shoham M: The basic and clinical pharmacology of nonpeptide vasopressin receptor antagonists. Annu Rev Pharmacol Toxicol 2001;41: 175-202.

34 Gheorghiade M, Gattis WA, Barbagelata A, et al: Rationale and study design for a multicenter, randomized, double-blind, placebocontrolled study of the effects of tolvaptan on the acute and chronic outcomes of patients hospitalized with worsening congestive heart failure. Am Heart J 2003;145(suppl 2): S51-S54.
35 Goldsmith SR: Vasopressin: a therapeutic target in congestive heart failure? J Card Fail 1999;5:347-356.

36 Nielsen S: Renal aquaporins: an overview. BJU Int 2002;90(suppl 3):1-6.

37 Tian Y, Sandberg K, Murase T, et al: Vasopressin V2 receptor binding is down-regulated during renal escape from vasopressininduced antidiuresis. Endocrinology 2000; 141:307-314.

38 Ecelbarger CA, Chou CL, Lee AJ, et al: Escape from vasopressin-induced antidiuresis: role of vasopressin resistance of the collecting duct. Am J Physiol 1998;274:F1161F1166.

39 Bartter FC, Schwartz WB: The syndrome of inappropriate secretion of antidiuretic hormone. Am J Med 1967;42:790-806.

40 Kovacs L, Robertson GL: Syndrome of inappropriate antidiuresis. Endocrinol Metab Clin North Am 1992;21:859-875.

41 Kinzie BJ: Management of the syndrome of inappropriate secretion of antidiuretic hormone. Clin Pharm 1987;6:625-633.

42 Oh MS: Pathogenesis and diagnosis of hyponatremia. Nephron 2002;92(suppl):2-8.

43 Harrigan MR: Cerebral salt wasting syndrome. Crit Care Clin 2001;17:125-138.

44 Chung HM, Kluge R, Schrier RW, et al: Postoperative hyponatremia. A prospective study. Arch Intern Med 1986;146:333-336.

45 Bouman WP, Pinner G, Johnson H: Incidence of selective serotonin reuptake inhibitor (SSRI) induced hyponatraemia due to the syndrome of inappropriate antidiuretic hormone (SIADH) secretion in the elderly. Int J Geriatr Psychiatry 1998;13:12-15.

46 Fabian TJ, Amico JA, Kroboth PD, et al: Paroxetine-induced hyponatremia in the elderly due to the syndrome of inappropriate secretion of antidiuretic hormone (SIADH). J Geriatr Psychiatry Neurol 2003;16:160-164.

47 Fabian TJ, Amico JA, Kroboth PD, et al: Paroxetine induced hyponatremia in older adults: a 12-week prospective study. Arch Intern Med 2004;164:327-332.

48 Rosner MH: Severe hyponatremia associated with the combined use of thiazide diuretics and selective serotonin reuptake inhibitors. Am J Med Sci 2004;327:109-111.

49 Kugler JP, Hustead T: Hyponatremia and hypernatremia in the elderly. Am Fam Physician 2000;61:3623-3630.

-50 Ayus JC, Arieff AI: Abnormalities of water metabolism in the elderly. Semin Nephrol 1996;16:277-288

51 Phillips PA, Rolls BJ, Ledingham JG, et al: Reduced thirst after water deprivation in healthy elderly men. N Engl J Med 1984;311: 753-759.

52 Ledingham JG, Crowe MJ, Forsling ML, et al: Effects of aging on vasopressin secretion, water excretion, and thirst in man. Kidney Int Suppl 1987;21:S90-S92. 
53 Creager MA, Faxon DP, Cutler SS, et al: Contribution of vasopressin to vasoconstriction in patients with congestive heart failure: comparison with the renin-angiotensin system and the sympathetic nervous system. J Am Coll Cardiol 1986;7:758-765.

54 Schrier RW, Fassett RG: Pathogenesis of sodium and water retention in cardiac failure. Ren Fail 1998;20:773-781.

55 Kalra PR, Anker SD, Coats AJ: Water and sodium regulation in chronic heart failure: the role of natriuretic peptides and vasopressin. Cardiovasc Res 2001;51:495-509.

56 Goldsmith SR, Gheorghiade M: Vasopressin antagonism in heart failure. J Am Coll Cardiol 2005;46:1785-1791.

57 Goldsmith SR: Current treatments and novel pharmacologic treatments for hyponatremia in congestive heart failure. J Am Coll Cardiol 2005;95:14B-23B.

58 Lee DS, Austin PC, Rouleau JL, et al: Predicting mortality among patients hospitalized for heart failure: derivation and validation of a clinical model. JAMA 2003;290:25812587.

59 Gines P, Berl T, Bernardi M, Bichet DG: Hyponatremia in cirrhosis: from pathogenesis to treatment. Hepatology 1998;28:851-864.

60 Gerbes AL, Gulberg V: Therapy of hyponatremia in cirrhosis with a vasopressin receptor antagonist: a randomized double-blind multicenter trial. Gastroenterology 2003; 124:933-939.

61 Palm C, Gross P: V2-vasopressin receptor antagonists-mechanism of effect and clinical implications in hyponatraemia. Nephrol Dial Transplant 1999;14:2559-2562.

-62 Palm C, Reimann D, Gross P: The role of V2 vasopressin antagonists in hyponatremia. Cardiovasc Res 2001;51:403-408.

63 Andreoli TE: Water: normal balance, hyponatremia, and hypernatremia. Ren Fail 2000; 22:711-735

-64 Ohnishi A, Orita Y, Okahara R, et al: Potent aquaretic agent. A novel nonpeptide selective vasopressin 2 antagonist (OPC-31260) in men. J Clin Invest 1993;92:2653-2659.

65 Ohnishi A, Orita Y, Takagi N, et al: Aquaretic effect of a potent, orally active, nonpeptide V2 antagonist in men. J Pharmacol Exp Ther 1995;272:546-551.
66 Burrell LM, Phillips PA, Risvanis J, et al: Long-term effects of nonpeptide vasopressin V2 antagonist OPC-31260 in heart failure in the rat. Am J Physiol 1998;275:H176-H182.

67 Burrell LM, Risvanis J, Johnston CI, et al: Vasopressin receptor antagonism-a therapeutic option in heart failure and hypertension. Exp Physiol 2000;85:259S-265S.

68 Udelson JE, Smith WB, Hendrix GH, et al: Acute hemodynamic effects of conivaptan, a dual V1A and V2 vasopressin receptor antagonist, in patients with advanced heart failure. Circulation 2001;104:2417-2423.

69 Serradeil-Le Gal C, Wagnon J, Valette G, et al: Nonpeptide vasopressin receptor antagonists: development of selective and orally active V1A, V2 and V1B receptor ligands. Prog Brain Res 2002;139:197-210.

70 Goldsmith SR: Vasopressin antagonists in CHF: ready for clinical trials? Cardiovasc Res 2002;54:13-15.

71 Decaux G: Difference in solute excretion during correction of hyponatremic patients with cirrhosis or syndrome of inappropriate secretion of antidiuretic hormone by oral vasopressin V2 receptor antagonist VPA-985. J Lab Clin Med 2001;138:18-21.

72 Wong F, Blei AT, Blendis LM, Thuluvath PJ: A vasopressin receptor antagonist (VPA985) improves serum sodium concentration in patients with hyponatremia: a multicenter, randomized, placebo-controlled trial. Hepatology 2003;37:182-191.

73 Gheorghiade M, Niazi I, Ouyang J, et al: Vasopressin V2-receptor blockade with tolvaptan in patients with chronic heart failure: results from a double-blind, randomized trial. Circulation 2003;107:2690-2696

74 Gheorghiade M, Gattis WA, O'Connor CM, et al: Effects of tolvaptan, a vasopressin antagonist, in patients hospitalized with worsening heart failure: a randomized controlled trial. JAMA 2004;291:1963-1971.

75 Saito T, Ishikawa S, Abe K, et al: Acute aquaresis by the nonpeptide arginine vasopressin (AVP) antagonist OPC-31260 improves hyponatremia in patients with syndrome of inappropriate secretion of antidiuretic hormone (SIADH). J Clin Endocrinol Metab 1997;82:1054-1057.
76 Inoue T, Ohnishi A, Matsuo A, et al: Therapeutic and diagnostic potential of a vasopressin-2 antagonist for impaired water handling in cirrhosis. Clin Pharmacol Ther 1998;63:561-570.

77 Martinez-Castelao A: Conivaptan (Yamanouchi). Curr Opin Investig Drugs 2002;3: 89-95.

78 Burnier M, Fricker AF, Hayoz D, et al: Pharmacokinetic and pharmacodynamic effects of YM087, a combined V1/V2 vasopressin receptor antagonist in normal subjects. Eur J Clin Pharmacol 1999;55:633-637.

79 Abraham WT, Suresh DP, Wagoner LE, et al: Pharmacotherapy for hyponatremia in heart failure: effects of a dual V1A/V2 vasopressin antagonist YM087 (abstract 1562). Circulation 1999;100(suppl):I-299.

80 Abraham W, Suresh DP, Wagoner LE, et al: Pharmacotherapy for hyponatremia in heart failure: effects of a new combined vasopressin V1A/V2 receptor antagonist, conivaptan (YM087) administered orally (abstract 1849). Eur Heart J 2000;21:345.

81 Abraham W, Koren M, Bichet DG, et al: Treatment of hyponatremia in patients with SIADH or CHF with intravenous conivaptan (YM087), a new combined vasopressin V1A/ V2 receptor antagonist (abstract 1848). Eur Heart J 2000;21:345.

82 Bichet DG, Madore F, Cusson J, et al: Pharmacotherapy for hyponatremia in SIADH: effects of a new orally administered V1A/V2 antagonist YM087 (abstract A0613). J Am Soc Nephrol. 1999;10:119A.

83 Verbalis JG, Bisaha J, Smith N: Novel vasopressin V1A and V2 antagonist conivaptan increased serum sodium concentration and effective water clearance in a hyponatremia clinical trial (abstract SA-P0254). J Am Soc Nephrol 2004;15:356A.

84 Gross P, Bisaha J, Smith N: Conivaptan, a novel V1A/V2 antagonist, increased serum sodium and effective water clearance in a hyponatremia clinical trial. (abstract SAP2043). J Am Soc Nephrol 2004;15:353A.

85 Ghali JK, Bisaha J, Smith N: Efficacy of the vasopressin V1A/V2 antagonist conivaptan in a clinical trial of euvolemic or hypervolemic hyponatremia (abstract SA-P0252). J Am Soc Nephrol 2004; 15:355A. 